\title{
Effectiveness of the Video Assisted Teaching Program on Thermal Protection of Newborns among Mothers in a Selected Hospital at Mangalore
}

\author{
Laxmi Paudyal $^{1}$, Nitu Singh Gautam ${ }^{2}$ \\ ${ }^{1,2}$ Lecturer Advanced Child Health Nursing \\ Gandaki Medical College Teaching Hospital and Research center (GMCTHRC)
}

\begin{abstract}
The Child is always precious so their health too. The maintenance of child health is desired and positively taken so every society has goal of improved level of child health status. Neonatal care begins from premarital age which continues from conception, pregnancy, and childbirth and to the childhood through proper care during each stage. When primary neonatal care is inadequate, then it leads to unavoidable and unacceptable high neonatal morbidity and mortality occurs. Among the concerned care thermal protection of newborn is also one of them since hypothermia is considered silent killer among neonate. To make aware regarding this condition with the aim to find the effectiveness of video assisted teaching program on thermal protection of newborns among mothers this study was conducted. Researcher used an evaluatory approach with a pre experimental, one group pre-test post test design in the study. A self prepared knowledge questionnaire was used to assess the knowledge among mothers on thermal protection of newborns followed by video assisted teaching program and again followed by same questionnaire for post test. Split half method was used to test tool reliability and found that tool was reliable $(r=0.86 ; p<0.05)$. To select sample of 50 mothers from a maternity hospital non probability purposive sampling technique was used. Findings revealed that the post test knowledge score $(15.12 \pm 3.41)$ was higher than pretest knowledge score $(9.68 \pm 3.27)$. The calculated' $t$ ' value in knowledge $(8.895 \mathrm{p}<0.005)$ was greater than the table value (1.677). Study found significant association between the pre-test knowledge level on thermal protection of newborn among mothers and selected baseline variables. Study concluded that the video assisted teaching program was highly effective in improving the knowledge of mothers on thermal protection of newborns.
\end{abstract}

Keywords:- Effectiveness, Knowledge, Video assisted teaching program, Newborn, Thermal protection, Mothers, Selected hospital.

\section{INTRODUCTION}

A Newborn baby is a lovely and precious gift to the mother. Birth of a healthy newborn is always expected precious not only to his parents and family but also to community, nation and to the world and one of the finest gifts of nature. The period from birth to 28 days is considered neonatal period and the infant in this period are termed as neonate or newborn baby. The newborn after birth goes under various changes and have to adopt different physiological mechanisms for survival (Guha, 2003). After birth a baby's body temperature can fall very quickly due to less body fat in the body (World Health Organization [WHO], 2012). Newborns maintained body temperature controlled by the hypothalamus and mediated by endocrine pathways through shivering and nonshivering thermo genesis (Guha, 2003). The healthy full term baby and normal weight baby will try to maintain his temperature within the normal range by various means but particularly in premature and low birth weight infants, thermoregulatory mechanisms are easily affected, leading to hypothermia which ultimately leads to metabolic deterioration and direct death or indirect mortality from associated morbidities such as severe infections (Lunze, Bloom, Jamison and Hamer, 2013).

Hypothermia is a condition in which the body temperature is below the normal range $\left(37^{\circ} \mathrm{C}\right)$ (Guha, 2003). Although hypothermia is rarely a direct cause of death, it contributes to a substantial proportion of neonatal mortality globally, mostly as a co morbidity of severe neonatal infections, preterm birth, and asphyxia (Lunze, Bloom, Jamison and Hamer, 2013). Hypothermia also is associated with hypoglycemia, respiratory distress, and metabolic acidosis (Mannan, Jagetheesan, DeSandre, Song, Showalter and Govindaswami, 2013). Hypothermia is common in infants born at hospitals and home with the prevalence range, $32 \%$ to $85 \%$ and $11 \%$ to $92 \%$, respectively even in tropical environments (Lunze, Bloom, Jamison and Hamer, 2013). The incidence of hypothermia is between $31 \%$ and $78 \%$ for those with birth weight less than $1500 \mathrm{gm}$. Infants at less than 28 weeks' gestation have the highest incidence of hypothermia (Madhu, Jagetheesan, DeSandre, Song, Showalter and Govindaswami, 2013). Very Low Birth weight babies were 11.63 times more likely than normal weight infants to have axillary temperatures $<35.0^{\circ} \mathrm{C}$ (Scrafford, Mullany and Katz et al., 2013). 
About four million neonatal deaths occur every year globally; among them almost (99\%) deaths arise in low and middle income countries. In India only, around one million babies die each year within one month life which contributes to one-fourth of the global burden. In India neonatal mortality rate is 76 and 34 per 1000 live birth in rural and urban area respectively. The most common causes of neonatal deaths in India include infections, birth asphyxia, and prematurity and hypothermia which contribute to $32.8 \%$. $22.3 \%$ and $16.8 \%$ of total neonatal deaths respectively. (World Health Organization [WHO], 2010). Many babies whose body temperature falls below $30-32^{\circ} \mathrm{C}$ will not survive. Neonatal hypothermia continues to be very important causes of neonatal deaths (Choudhary, 2005). Hypothermia occurs when the newborns body temperature drops below $36.5^{\circ} \mathrm{C}\left(97.7^{\circ} \mathrm{F}\right)$ generally because the environment is too cold for the baby. (Guha, 2003). It is considered as the silent killer of the newborn. According to UNICEF Prevention and management of hypothermia can help reduce neonatal mortality or morbidity by $18 \%-42 \%$.

Thermoregulation is the process that allows the human body to maintain its core internal temperature. After birth the infant is exposed to outside environment where they experience relatively lower temperature than in intrauterine environment so that they face life threatening conditions in terms of maintaining body temperature (Guha, 2003). The main cause of rapid heat loss and consequent hypothermia in newborn is because they have high body surface to volume ratio which is again high among low birth weight neonates. Newborn loss heat from their body by four means they are: 1) When uncovered skin of newborn is exposed to an environment containing objects of cooler temperature through radiation, 2) When neonates are wet with amniotic fluid loss and heat loss through evaporation, 3) Conductive heat loss occurs when the neonate is placed in contact with a cool surface or object and 4) through convection when newborn is exposed to cool area (WHO, 2012). The risk factors of neonatal hypothermia are separation of baby from mother, cold environment, and change of temperature, inadequate warming, excessive loss of heat, premature, low apgar scores, infants of multiple pregnancies and those who received cardiopulmonary resuscitation had higher risk for being hypothermia (WHO, 2010; Fraser, Copper and Myles, 2004). The various clinical signs shown by hypothermic neonates are skin temperature below 36.5 degree centigrade, extremities are bluish and cold to touch, weak and lethargy, slow and irregular heart rate and respiration. Hypothermia leads to various health consequences such as hypoxia, hypoglycemia, respiratory distress, hyperbilirubinemia, impaired cardiac function and death (Fraser, Copper and Myles, 2004). To prevent neonates from Hypothermia the warm chain should be maintain with the set of ten interlinked procedures carried out soon after birth and followed later too. They are: 1) Warm delivery room $\left.\left(>25^{\circ} \mathrm{C}\right), 2\right)$ Warm resuscitation, 3) Immediate drying, 4) Skin to skin contact between baby and mother, 5) breastfeeding initiated soon after delivery, 6) postponed bathing and weighing until baby is warm, 7) Appropriate clothing and bedding, 8) Mother and baby together, 9) Warm transportation and 10) Training/ awareness of health care providers (WHO, 2010; Lunze et al., 2014; Byarunhanga and Bergstorm, 2005).

The World Health Organization [WHO] recognizes thermal care of newborn as a critical and essential component of essential newborn care where hypothermia is continue to remain under recognized under documented and under managed so that facing difficulty to reduce the neonatal morbidity and mortality (Kumar, Shearer, Kumar and Darmstadt, 2009). The lack of thermal protection is still an underappreciated major challenge for newborn survival in developing countries (Lunze, Bloom, Jamison and Hamer, 2013). The knowledge deficiency among health care provider and primary care giver has sustained the silent epidemic of hypothermia (Kumar, Shearer, Kumar and Darmstadt, 2009; Dongre, Deshmukh and Garg, 2008). A cross-sectional descriptive study was conducted among 300 newborns in Uganda to determining the prevalence of neonatal hypothermia and associated risk factors revealed that knowledge regarding thermal protection of the newborn is very essential to prevent hypothermia ( Zayeri et al., 2014). A descriptive study conducted in New Jersey to find out the level of knowledge of mothers of neonates about the prevention of heat loss and the promotion of adequate body heat revealed that the $55 \%$ mothers had inadequate knowledge, $30 \%$ mothers had average knowledge and only $15 \%$ mothers had adequate knowledge. Study concluded that mothers are still needs more knowledge to prevent the baby from heat loss (Oinam and Kharde, 2015). A single blind randomized control trial was done to assess the effectiveness of video assisted teaching program on knowledge regarding essential newborn care among primipara mothers in Belgaum Karnataka. Results shown that the mean post test knowledge score $28.47+-2.67$ is higher than the mean pretest knowledge score $16.33+-3.54$ of study group as compared to control group. Study concluded that video assisted teaching program was an effective method to increase the knowledge of mothers on essential newborn care (Bhandari, Karde and Raddi, 2015).

The above studies revealed that the neonatal hypothermia is the serious but potentially preventable condition. Lack of knowledge to primary care givers has sustained the silent epidemic of hypothermia. Mothers are the primary care givers for the infants after delivery and discharge from hospitals. With simple feasible care initiated for the newborn can save the life of neonates reducing about $40 \%$ of the neonatal mortality (Kumar, Shearer, Kumar and Darmstadt, 2009). The investigator felt that increasing the knowledge of the parents specially mothers in is the most applicable and appropriate way to prevent and manage the hypothermia in neonates. So that they can prevent and manage hypothermia as a result they can protect their neonates. Knowledge regarding thermal protection is needed to the caregivers of neonate and more especially to the mothers as they can assess the condition of neonates better than others as they were involved in care of neonates. By enriching the mother's knowledge regarding neonatal hypothermia and way to prevent and treat 
newborn hypothermia the mortality and morbidity of newborn can be reduced.

\section{METHODOLOGY}

This research aimed at assessing the effectiveness of video assisted teaching program regarding thermal protection of newborns among mothers in a selected hospital at Mangalore.

\section{Research approach and design}

An evaluative approach with pre-experimental, i.e., one group pre test post test design was found to be appropriate to describe the effectiveness of video assisted teaching program regarding thermal protection of newborns among mothers.

\section{Setting}

This study was conducted in a Government Ladygoschen hospital, Mangalore. Selection of the hospital for the study is on the basis of:

- Geographical proximity: The hospital is within 15 kilometers from college.

- Feasibility of conducting study: The mothers in the hospitals are co operative and most of them are kannada speaker who can read and understand kannada.

- Availability of sample: Hospital is 500 beded Government Maternity Hospital. Per day around than 50 deliveries was occured normal as well as cesarean section.

\section{$>$ Sampling procedure}

The sample of the study would compromise of fifty mothers having newborn baby in selected hospital at Mangalore, fulfilling inclusion criteria. Non probability, Purposive sampling technique was used for the study, to select mothers from the selected hospital.

\section{Ethical Approval}

Ethical clearance was taken from institutional ethical review board Dr MV Shetty College of health sciences.

\section{Data collection technique}

In this study researcher has prepared knowledge questionnaire which consists 24 items has been used to collect data from mothers. Same questionnaire was used in pre and post test.
The tool was further divided into two parts.

Part I: Demographic performa- This is designed to obtain the demographic information from respondents consisting of eight items.

Part II: Semi strucured knowledge questionnaire

The investigator has prepared semi structured questionnaire after extensive literature review, expert's advice. The instrument is prepared in English and it is translated to local Kannada language and re translation English to check accurate meaning of the tool. The instrument is distributed on kannada language to the respondents are requested to respond the questions by putting tick mark to the options given as accurate as possible. After completion of questionnaire the video is shown to them on same pre testing day. Post test was given after 4 days of pre test with same questionnaire.

Each question had a score 1 for the correct answer and score 0 for the wrong answer.

Thus altogether there were 24 items with a maximum total score of 24 .

\section{RESULTS}

\section{* Organization of the findings}

The results have been organized and presented in 4 parts:

Part I: Description of demographic variables related to the mothers.

Part II: Assessment of knowledge of mothers regarding thermal protection of newborn.

Part III: Effectiveness of video assisted teaching program on knowledge regarding thermal protection of newborn.

Section A: Comparision of the level of knowledge in pre test with post test and effectiveness of study.

Section B: Area wise difference in Mean, S.D and mean percentage of pre est and post test score.

Part IV: Association between pretest knowledge scores of mothers regarding thermal protection of newborn and selected baseline variables.

\section{Part I: Description of demographic variables related to the mothers.}

The part I includes the distribution of participants according to their demographic characteristics. Data was summarized and presented on frequency and percentage. 


\begin{tabular}{|c|c|c|c|}
\hline S.No & Demographic variables & Frequency & Percentage (\%) \\
\hline 1 & Age in completed years & & \\
\hline A & $>20$ & 19 & 38 \\
\hline B & $20-25$ & 17 & 34 \\
\hline $\mathrm{C}$ & $26-30$ & 13 & 26 \\
\hline $\mathrm{D}$ & $31-35$ & 1 & 2 \\
\hline 2 & Religion & & \\
\hline A & Hindu & 32 & 64 \\
\hline B & Muslim & 18 & 36 \\
\hline 3 & Education & & \\
\hline A & Primary level & 22 & 44 \\
\hline B & Secondary level & 16 & 32 \\
\hline $\mathrm{C}$ & PUC and above & 12 & 24 \\
\hline 4 & Occupation & & \\
\hline A & Home maker & 26 & 52 \\
\hline B & Daily wages & 17 & 34 \\
\hline $\mathrm{C}$ & Private employee & 7 & 14 \\
\hline 5 & Family Income per month & & \\
\hline A & Below 50000 & 25 & 50 \\
\hline B & $50001-100000$ & 16 & 32 \\
\hline $\mathrm{C}$ & $1000001-1500000$ & 6 & 12 \\
\hline $\mathrm{D}$ & 1500001 and above & 3 & 6 \\
\hline 6 & Family type & & \\
\hline A & Nuclear & 25 & 50 \\
\hline B & Joint & 15 & 30 \\
\hline $\mathrm{C}$ & Extended & 10 & 20 \\
\hline 7 & Present type of Delivery & & \\
\hline A & Normal & 31 & 62 \\
\hline B & Vaccum & 5 & 10 \\
\hline $\mathrm{C}$ & Cesarean & 14 & 28 \\
\hline 8 & No of parity & & \\
\hline $\mathrm{A}$ & 1 & 22 & 44 \\
\hline B & 2 & 23 & 46 \\
\hline $\mathrm{C}$ & 3 & 5 & 10 \\
\hline
\end{tabular}

Table 1:- Distribution of respondents according demographic variables $(\mathrm{N}=50)$

Above table 2 represent that Majority 38\% of the mothers are below 20 years of age. Most of them 64\% are hindu. Majority $44 \%$ has completed their primary level of education. Most 52\% of mothers are home maker. Among the participants $50 \%$ had family income per month below 50000. Most 50\% are from nuclear family. Most $62 \%$ had normal delivery and majority $46 \%$ had II no of parity. 
Part II: Assessment of knowledge of mothers regarding thermal protection of newborn.

This part represents the distribution of the level of pre-test knowledge on thermal protection of newborns among mothers.

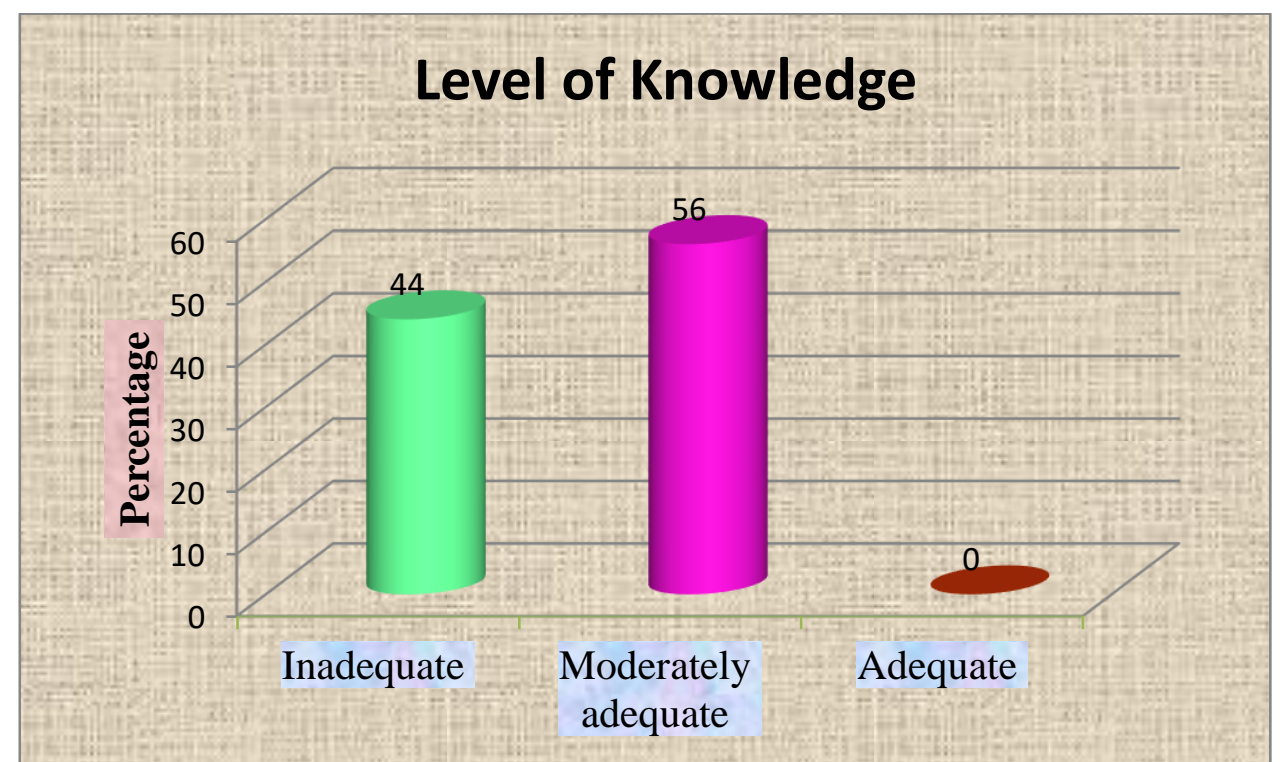

Fig 1:- The bar diagram showing percentage distribution of mothers according to level of knowledge

Data in the Figure 1 shows that Majority $56 \%$ of the mothers had moderately adequate knowledge and $44 \%$ had inadequate level of knowledge in pre test.

\section{Part III: Effectiveness of video assisted teaching program on knowledge regarding thermal protection of newborn.}

- Section A: Comparision of the level of knowledge in pre test with post test and effectiveness of study.

This part compares level of knowledge in pretest and post test and finds the effectiveness of the study. A null hypothesis was formulated.

$\mathrm{H}_{0} 1$ : There is no significant difference between pre-test and post test knowledge scores on thermal protection of newborn among mothers.

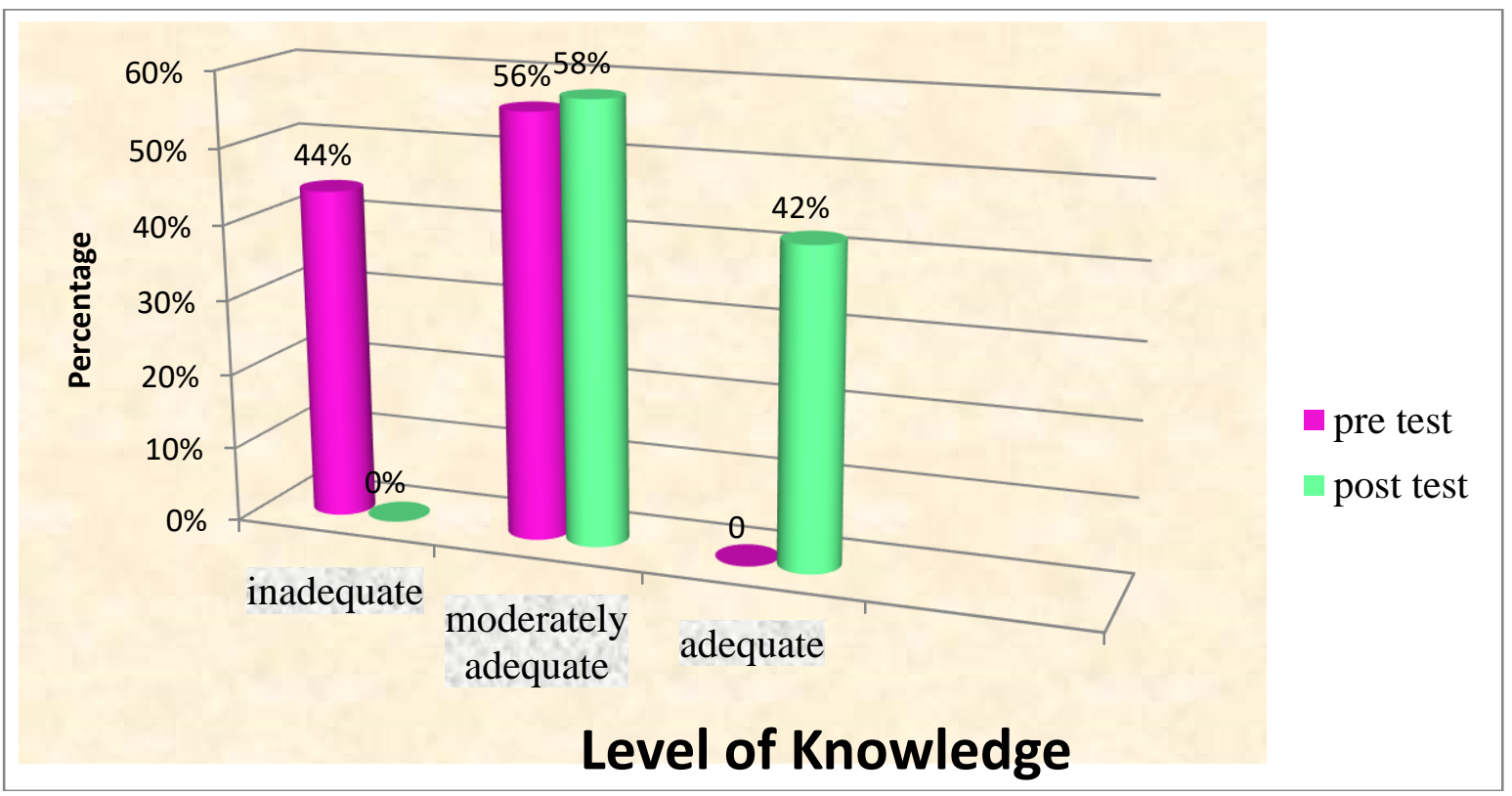

Fig 2:- Bar diagraming showing Comparision of level of knowledge and effectiveness in pre-test with post- test.

The data presented in the figure 2 shows that the $56 \%$ mothers had moderately adequate knowledge and $44 \%$ had inadequate knowledge in pre-test where as in post test $58 \%$ and $42 \%$ mothers had moderately adequate and adequate level of knowledge respectively. 
ISSN No:-2456-2165

\begin{tabular}{|c|c|c|c|c|c|c|c|c|}
\hline \multirow[t]{2}{*}{ Level of knowledge } & \multicolumn{3}{|c|}{ Pre test } & \multicolumn{3}{|c|}{ Post test } & \multirow{2}{*}{$\begin{array}{c}\text { Mean } \\
\text { difference }\end{array}$} & \multirow[t]{2}{*}{ t-test } \\
\hline & 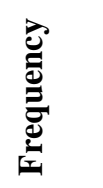 & 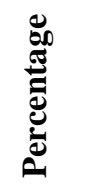 & $\sum_{\Sigma}^{\bar{\Xi}}$ & 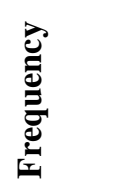 & 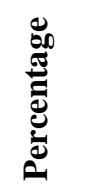 & $\stackrel{\text { }}{\Sigma}$ & & \\
\hline Inadequate & 22 & 44 & \multirow[t]{3}{*}{9.68} & 0 & 0 & \multirow[t]{3}{*}{15.12} & \multirow[t]{3}{*}{5.44} & \multirow[t]{3}{*}{$8.895^{*}$} \\
\hline Moderately adequate & 28 & 56 & & 29 & 58 & & & \\
\hline Adequate & 0 & 0 & & 21 & 42 & & & \\
\hline
\end{tabular}

Table 2:- Comparision of level of knowledge in pre-test with post- test and effectiveness of the study.

$(\mathrm{N}=50)$

The findings in the Table 2 revealed that the mean post test score was significantly higher than their mean pre test score. The calculated ' $t$ ' value $(8.895, \mathrm{p}<0.05)$ was greater than the table value $(1.677)$ at 0.05 level of significance. Therefore, the null hypothesis was rejected and concluded that, there is highly significant gain in knowledge of mothers on thermal protection of newborns in post test.

- Section B: Area wise Mean, S.D and mean percentage of pre test and post test score.

This part deals with area wise Mean, S.D and mean percentage of pre test and post test knowledge scores.

\begin{tabular}{|c|c|c|c|c|c|c|c|c|c|c|}
\hline \multicolumn{11}{|c|}{ Knowledge score } \\
\hline \multirow[t]{2}{*}{ Areas } & \multirow[b]{2}{*}{ 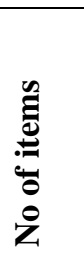 } & \multicolumn{3}{|c|}{ Pre-test (A) } & \multicolumn{3}{|c|}{ Post-test (B) } & \multicolumn{3}{|c|}{ Effectiveness (B-A) } \\
\hline & & Mean & $\begin{array}{c}\text { SD } \\
\pm\end{array}$ & $\begin{array}{c}\text { Mean } \\
(\%)\end{array}$ & Mean & $\begin{array}{c}\text { SD } \\
\pm\end{array}$ & $\begin{array}{c}\text { Mean } \\
(\%)\end{array}$ & Mean & $\begin{array}{c}\text { SD } \\
\pm\end{array}$ & $\begin{array}{c}\text { Mean } \\
(\%)\end{array}$ \\
\hline Area I & 6 & 2.24 & 1.21 & 37.33 & 4.46 & 1.23 & 74 & 2.22 & 0.02 & 36.67 \\
\hline Area II & 5 & 1.68 & 1.37 & 33.60 & 3 & 1.14 & 60 & 1.32 & 0.23 & 26.4 \\
\hline Area III & 13 & 5.76 & 2.56 & 44.31 & 7.66 & 1.94 & 58.92 & 1.90 & 0.62 & 14.61 \\
\hline Total & 24 & 9.68 & 3.27 & 40.33 & 15.12 & 3.41 & 63 & 5.44 & 0.14 & 22.67 \\
\hline
\end{tabular}

Table 3:- Area wise Mean, S.D, mean percentage and mean difference of pre test and post test scores.

The data presented in the Table 3 shows that the total mean knowledge score is increased by 22.67 mean percentage with mean \pm SD of $5.44 \pm 0.14$ after the administration of video assisted teaching programme.

Comparision of the area wise mean and SD of the knowledge score showed that, the effectiveness of video assisted teaching programme in the Area I introduction and meaning of neonatal hypothermia had increase in the mean percentage knowledge scores by $36.67 \%$ with the mean and SD of $2.22 \pm 0.02$. In the Area II causes and symptoms of neonatal hypothermia and Area III prevention and management of neonatal hypothermia the mean percentage is increased by 26.4 and $14.61 \%$ with mean and SD of $1.32 \pm 0.23$ and $1.90 \pm 0.62$ respectively. The results reveal that overall knowledge level was inadequate and moderately adequate in pretest as the post test knowledge scores come under moderately adequate annd adequate knowledge level.

Part IV: Association between pretest knowledge scores of mothers regarding thermal protection of newborn and selected baseline variables.

To check the association between the knowledge of the respondents and selected demographic variables chisquare test was computed and the following null hypothesis was formulated.

$\mathbf{H}_{0}$ 2: There is no significant association between pretest knowledge scores on thermal protection of newborn among mothers and selected baseline variables. 
ISSN No:-2456-2165

\begin{tabular}{|c|c|c|c|c|}
\hline Demographic variables & $\chi^{2}$ & $\begin{array}{c}\text { Knowledge } \\
\text { Df }\end{array}$ & Inference & Table value \\
\hline Age in completed years & 1.687 & 3 & NS & 7.82 \\
\hline Religion & 5.85 & 1 & $\mathbf{S}$ & 3.84 \\
\hline Education & 20.33 & 2 & $\mathbf{S}$ & 5.99 \\
\hline Occupation & 33.57 & 2 & $\mathbf{S}$ & 5.99 \\
\hline Family income & 9.67 & 3 & $\mathbf{S}$ & 7.82 \\
\hline Family type & 14.39 & 2 & NS & 5.99 \\
\hline Type of delivery & 1.385 & 2 & $\mathbf{S}$ & 5.99 \\
\hline No of parity & 6.92 & 2 & & $\mathbf{S}$ \\
\hline
\end{tabular}

Table 4:- Association between pre test knowledge score with selected demographic variables. $(\mathrm{N}=50)$ $\mathrm{df}=$ Degree of freedom $\mathrm{S}=$ Significant; NS=Not significant

From the above Table 4 findings can be summarized as that the calculated chi-Square value of some sources like religion, education, occupation, family income, family type and No of parity are more than table value of chi-square on specific degree of freedom at 0.05 level of significance, hence the null hypothesis is rejected and concluded that there was significant association between the pre-test knowledge scores on thermal protection of newborn among mothers and selected baseline variables.

\section{DISCUSSION}

\section{Major findings}

Findings of demographic performa

- Majority $38 \%$ of the mothers are below 20 years of age.

- Majority $64 \%$ of them are hindu.

- Most of them $44 \%$ has completed their primary level of education.

- Highest $52 \%$ of mothers are home maker.

- Among the participants $50 \%$ had family income per month below 5000 .

- Most of them $50 \%$ are from nuclear family.

- Majority $62 \%$ had normal delivery.

- Highest $46 \%$ had II no of parity.

$>$ Findings of Level of knowledge of mothers on thermal protection of newborn

The assessment of the existing knowledge regarding thermal protection of newborns revealed that Majority $56 \%$ of the mothers had moderately adequate knowledge and $44 \%$ had inadequate level of knowledge. Where in post test $58 \%$ of mothers had moderately adequate knowledge and $42 \%$ had adequate level of knowledge.

Above findings was similar with the findings of quasi experimental study conducted on capital hospital, Bhubaneswar, Odisha with the objective to assess the effectiveness of structured teaching program on knowledge of mothers regarding prevention of hypothermia in newborns. Findings revealed that majority $58 \%$ mothers had moderately adequate knowledge and $42 \%$ had inadequate knowledge with no one having adequate knowledge in pre test but in post test $54 \%$ mothers had moderately adequate knowledge and $46 \%$ had adequate knowledge with no one having inadequate level of knowledge. ( Kumari and Bhadhei, 2015).

Effectiveness of video assisted teaching programme on thermal protection of newborn

The total mean knowledge score is increased by $22.67 \%$ with mean \pm SD of $5.44 \pm 0.14$ after the administration of video assisted teaching programme. The calculated ' $\mathrm{t}$ ' value $(8.895, \mathrm{p}<0.05)$ in was more than the table value (1.677) at 0.05 level of significance. Hence, it is concluded that, there is highly significant gain in knowledge of mothers on thermal protection of newborns.

The study findings was similar to the pre experimental study conducted in MMIMSR hospital, Mullana, Haryana with the objective to evaluate the video assisted teaching program on concept of thermal protection of newborns among 30 mothers. The results showed that mean post test knowledge $(22.97 \pm 6.19)$ is higher than the mean pretest knowledge (13.83 \pm 3.18$)$. The calculated ' $t$ ' value of 7.19 was found statistically significant at 0.05 level of significance. The study concluded that the video assisted teaching program is one of the effective methods to increase knowledge of mothers (Sood, Bala and Kumar, 2014).

Association between pretest knowledge scores of mothers on thermal protection and selected baseline variables

The association between pre test knowledge score and selected baseline variables is identified using chi-Square it revealed that the calculated chi-Square value of some sources like religion $\left(\chi^{2}=5.85\right)$ education $\left(\chi^{2}=20.33\right)$, occupation $\left(\chi^{2}=33.57\right)$, family income $\left(\chi^{2}=9.16\right)$, Type of family $\left(\chi^{2}=14.39\right)$ and No of parity $\left(\chi^{2}=6.92\right)$ are more than table value at 0.05 level of significance and calculated chi square value for the sources age in years and type of delivery is less than that of table value at 0.05 level of significance, hence the null hypothesis is rejected and concluded that there was significant association between 
the pre-test knowledge scores on thermal protection of newborn among mothers and selected baseline variables.

These study findings were similar with the pre experimental study conducted on Sri Chamarajendra hospital, Hassan with the objectives to evaluate the effectiveness of structured teaching program on the knowledge regarding measures of thermoregulation in newborns among mothers. The findings of $\chi^{2}$ revealed that the calculated $\chi^{2}$ values with regard to occupation $\left(\chi^{2}=5.03\right)$; family income $\left(\chi^{2}=8.05\right)$; type of family $\left(\chi^{2}=\right.$ $6.35)$; parity $\left(\chi^{2}=6.45\right)$; were more than the table values at 0.05 level of significance. It is concluded that, pre-test knowledge level of respondents are significantly associated with occupation, family income, type of family and parity (Malathi, 2015).

\section{CONCLUSION}

Neonatal hypothermia is prevalence but unrecognized in present scenario. Primary care givers and mothers should be aware about the thermal protection of newborns to prevent neonatal death from hypothermia. The study concluded that the video assisted teaching program will be significantly effective method to enhance mother's knowledge.

\section{REFERENCES}

[1]. Bhandari MU, Kharde NS and Raddi AS (2010) A study to evaluate the effectiveness of planned teaching program on knowledge of mothers on prevention of hypothermia among newborn in selected hospital hospitals of Belgaum, Karnataka. South Asian Federation of obstretics and Gynaecology; 2(1):89-92 Available

From: https://pdfs.semanticscholar.org/3559/2861b14cddf11 58615ada31af732eb37631d.pdf

[2]. Byaruhanga R, Bergstrom A and Okong P (2005) Neonatal hypothermia in Uganda: prevalence and risk factors. $J$ Trop Pediatr; 51(4):212-215. doi:10.1093/tropej/fmh098 Available From: https://pubmed.ncbi.nlm.nih.gov/15917265/

[3]. Choudhary SP (2004) Principals of pediatric nursing and neonatal emergencies. 2nd edition. New Delhi: Jaypee Publication: page no 563-566

[4]. Dongre AR, Deshmukh PR and Garg BS (2008) Perceptions and health care seeking about newborn danger signs among mothers in rural Wardha. Indian $J$ Pediatr 75, 325-329:

DOI: https://doi.org/10.1007/s12098-008-0032-7. Available From:

https://link.springer.com/article/10.1007/s12098-0080032-7\#citeas

[5]. Fraser D, Cooper MA and Myles MF (2003) Myles Textbook for Midwives. 14th edition China: Churchill Livingstone: $\mathrm{Pp}$ 802-803

[6]. Guha DK (2005) Guha's NEONATOLOGY Principles and practice. 3rd edition. Volume I. Japyee the health science publishers New delhi
[7]. Kumar V, Shearer JC, Kumar A and Darmstadt GL (2009) Neonatal hypothermia in low resource settings: a review. J Perinatol.; 29(6):401-412. DOI:10.1038/jp.2008.233 available from: https://pubmed.ncbi.nlm.nih.gov/19158799/

[8]. Kumari DS and Badhei K (2015) Impact of Structured Teaching Programme (STP) on knowledge among the mothers of Newborn Regarding Prevention of Neonatal Hypothermia in a Selected Hospital, Bhubaneswar, Odisha, India: IOSR Journal of Nursing and Health Science (IOSR-JNHS); 4(2) PP 46-50 www.iosrjournals.org DOI: 10.9790/1959-04214650

[9]. Lunze L, Bloom ED, Jamison TD and Hamer HD (2013) The global burden of neonatal hypothermia: systematic review of a major challenge for newborn survival; $\quad B M C \quad$ Med 11, 24 DOI:https://doi.org/10.1186/1741-7015-11-24 Available From: http://www.biomedcentral.com/1741-7015/11/24

[10]. Lunze K, Yeboah-Antwi K, Marsh DR, Kafwanda $\mathrm{SN}$, Musso A, Semrau K, Waltensperger KZ, and Hamer DH (2014) Prevention and management of neonatal hypothermia in rural Zambia. PloS one, 9(4), e92006. https://doi.org/10.1371/journal.pone.0092006 Available

From: http://www.ncbi.nlm.nih.gov/pmc/articles/PM C3979664/

[11]. Malathi K (2015) Effectiveness of Structured Teaching Programme on Knowledge Regarding Measures of Thermoregulation in Newborn among Postnatal Mothers. AIJRHASS, 15-528; 2328: Available online at: http://www.iasir.net

[12]. Manani M, Jegatheesan P, DeSandre G, Song D, Showalter L, and Govindaswami B (2013) Elimination of admission hypothermia in preterm very low-birth-weight infants by standardization of delivery room management. The Permanente journal, 17(3), 8-13 DOI: https://doi.org/10.7812/TPP/12-130 Available from: https://www.ncbi.nlm.nih.gov/pmc/articles/PMC3783 084/

[13]. Oinam MD and Kharde S (2015) A RCT on effectiveness of VATP on knowledge regarding essential newborn care among primipara mothers in postnatal ward of selected hospital, belgaun Karnataka, IJSR Vol 4(6); Available from: https://www.ijsr.net/get_abstract.php?paper_id=SUB1 55952

[14]. Scrafford CG, Mullany LC, Katz J, et al (2013) Incidence of and risk factors for neonatal jaundice among newborns in southern Nepal. Trop Med Int Health 18(11):1317-1328. doi:10.1111/tmi.12189 Available from: http://www.ncbi.nlm.nih.gov/pmc/articles/PMC29113 $89 /$

[15]. Sood A, Bala J and Kumar Y (2014) Effectiveness of the video assisted teaching program regarding the concept of thermal protection of neonates IOSR Journal of Nursing and Health Science (IOSR-JNHS) 3(2) Ver. II PP 01-06 Available from www.iosrjournals.org 
[16]. WHO. Essential newborn care: Report of WHO technical working group. Series No: 424 Geneva. WHO,

FRH/MSM/1996;96.13 https://www.who.int/gho/publications/world_health_st atistics/EN_WHS2012_Full.pdf?ua=1

[17]. WHO: Thermal control of newborn: A Practical Guide (2012)

https://apps.who.int/iris/bitstream/handle/10665/6004 2/WHO_FHE_MSM_93.2.pdf;jsessionid=A9001A49 68229FA5B024A4F024787BD0? sequence $=1$

[18]. Zayeri F, Kazemnejad A, Ganjali M, Babaei G, Khanafshar N and Nayeri F (2005). Hypotherimia in Iranian newborns. Incidence, risk factors and related complications. Saudi Med J. 26 (9):1367-1371. Available from: https://pubmed.ncbi.nlm.nih.gov/16155649/ 